\title{
Efeitos do Ciclo Menstrual \& Uso de contraceptivo hormonal na performance
}

- As flutuações hormonais que ocorrem durante o ciclo menstrual podem estar associadas a mudanças na prática esportiva, uma vez que interferem na termorregulação, metabolismo, qualidade do sono, parâmetros cognitivos e desequilíbrios hídricos;

- Um dos mecanismos que justifica estas mudanças está baseado na sinalização do estradiol em vias metabólicas, que estimulam biogênese mitocondrial, produção de óxido nítrico e proliferação de células satélites;

- Entretanto, alguns estudos mostram que as flutuações hormonais isoladas não são determinantes de performance. Um estudo realizado com jogadoras de futebol que não faziam uso de anticoncepcionais não indicou mudanças na performance de forma significativa com as flutuações hormonais observadas ao longo do ciclo menstrual;

- Outro estudo, que também teve como objetivo relacionar as mudanças hormonais do ciclo menstrual e performance, indicou resultado relevante em termos de alterações no exercício. Entretanto, os autores enfatizam que as mudanças climáticas observadas ao longo do estudo poderiam interferir na performance e, portanto, não podemos afirmar que estas alterações hormonais isoladas geram mudanças na performance esportiva;

- Algumas análises colocam como hipótese que as alterações hormonais observadas em nível plasmático podem não refletir o que, de fato, ocorre no músculo;

- Também é sugerido que o processo adaptativo seja mais determinante para a performance quando comparado com apenas uma variável hormonal;

- Com o uso de contraceptivos orais observa-se que algumas condições ficam mais enfatizadas. O estresse oxidativo causado pelos contraceptivos orais pode justificar alguns sintomas que interferem na performance. Entretanto, o efeito adaptativo do treinamento é de extrema relevância, superando estes possíveis efeitos maléficos;

- Ainda, é necessário ter cautela com as possíveis deficiências nutricionais que estão atreladas ao uso de contraceptivos orais. Dentre os desequilíbrios nutricionais, a deficiência de ferro e vitaminas do complexo B ganham maior evidência e, portanto, precisam ser priorizados por meio de uma alimentação saudável;

- De forma complementar, estudos sugerem o aumento no consumo de alimentos fontes de compostos bioativos e ômega-3, com o objetivo de equilibrar o sistema oxidativo e reduzir reações inflamatórias.

\section{Referências bibliográficas}

1. THOMAS, A.; BUNYAN, K.; TIDUS, P.M. Oestrogen receptor-alpha activation augments post-exercise myoblast proliferation. Acta Physiol; 198(1):81-9, 2010.

2. JULIAN, R.; HECKSTEDEN, A.; FULLAGAR, H.H. et al. The effects of menstrual cycle phase on physical performance in female soccer players. PLoS One; 12(3): e0173951, 2017.

3. PAULI, S.A.; BERGA, S.L. Athletic amenorrhea: energy déficit or psychogenic challenge? Ann N Y Acad Sci; 1205:33-8, 2010.

4. CREWTHER, B.T.; HAMILTON, D.; KILDUFF, L.P. et al. The effect of oral contraceptive use on salivar testosterone concentrations and athlete performance during international field hockey matches. J Sci Med Sport; 21(5):453-456, 2018.

5. WANG, Q.; WURTZ, P.; AURO, K. et al. Effects of hormonal contraception on systemic metabolismo: cross-sectional and longitudinal evidence. Int J Epidemiol; 45(5):1445-1457, 2016. 